\title{
Pneumon in 2021: Entering a new e-Era
}

Konstantinos Kostikas ${ }^{1,2,3}$

'It is during our darkest moments that we must focus to see the light' Aristotle Onassis

As the COVID-19 pandemic still stands, at a time that all respiratory physicians have an additional specialty as 'covid-ologists' and the world suffers from the greatest pandemic of modern times, it is with great honor that I have accepted the invitation from the Hellenic Thoracic Society to serve its Journal, Pneumon, as the new Editor-in-Chief. Following the excellent leadership of Professor Demosthenes Bouros, the previous Editor-in-Chief, and having served the journal in the past as Associate Editor, I understand fully the importance and the challenges of the role. Pneumon has been the emblematic journal of respiratory medicine in Greece since 1987, historically supported by the leadership of the Hellenic respiratory community, providing access to knowledge and information to our colleagues as a bilingual journal in Greek and English, initially in its printed format and in the latest years in both printed and electronic editions.

We proudly announce that Pneumon is now entering a new electronic era, with its transformation to an Open Access journal published only in English and exclusively in paperless electronic format in its newly designed website (http:// www.Pneumon.org), under the support of the excellent team of European Publishing. Within this new era, our aspiration is that Pneumon will be shifting focus and opening to a wider international audience, with broader readership and authorship.

Based on its scope, Pneumon publishes original papers of international interest on laboratory and clinical research that are pertinent to lung biology and disease. Clinical and experimental work dealing with the whole field of pulmonology, including allied healthcare, cell and molecular biology, epidemiology, immunology, pathology, pharmacology, physiology, intensive and critical care, pediatric respiratory medicine, thoracic surgery, and digital developments in respiratory medicine are within the scope of the journal.

Following a fast transformative process, Pneumon now proudly adheres to best practices in open access academic publishing including to the Commission on Publication Ethics (COPE) Code of Conduct and Best-Practice Guidelines for Journal Editors ${ }^{1}$, and the International Committee on Medical Journal Editors (ICMJE's) Recommendations for the Conduct, Reporting, Editing and Publication of Scholarly Work in Medical Journals ${ }^{2}$. Furthermore, to ensure digital preservation for the future, the journal's electronic publications are archived with Portico, a third-party preservation service supported by both libraries and publishers, to ensure that scholarly content published in electronic form will remain accessible for the long-term. Moreover, readers will note that now important aspects such as the inclusion of statements on funding, data availability, ethical approval and informed consent, provenance, and the peer review process, are all now presented within the final typeset PDF versions of the manuscripts.

Pneumon is already indexed at the time of writing of this editorial in international databases such as SCOPUS, EMBASE and Copernicus Index, while we are striving towards indexing within other scientific databases. To

\author{
AFFILIATION \\ 1 Respiratory Medicine Department, Medical \\ School, University of Ioannina, Ioannina, \\ Greece \\ 2 Respiratory Medicine Department, \\ University Hospital of Ioannina, Ioannina, \\ Greece \\ 3 Respiratory Medicine, Observational and \\ Pragmatic Research Institute, Singapore, \\ Singapore
}

\section{CORRESPONDENCE TO}

Konstantinos Kostikas. Respiratory Medicine Department, Medical School, University of Ioannina, 45110, Ioannina, Greece. E-mail: ktkostikas@gmail.com ORCID ID: https:// orcid.org/0000-0003-0774-3942

\section{KEYWORDS}

editorial, pulmonology, respiratory medicine

Received: 17 October 2021

Accepted: 21 October 2021 
qualify for indexing in international databases, the journal must demonstrate strong quality control mechanisms, an international readership, and a growing number of highquality publications. In this direction, we are building a new Editorial Board of internationally acknowledged experts in the wider field of Respiratory Medicine to support the editorial process and scope of Pneumon.

As we are entering a new electronic era of communications and information exchange, with all the positive learnings from the pandemic, we must now focus on the improvement of the quality of the editorial process and the publications, to ensure that Pneumon will rise to the standards of a modern Journal hosting innovative publications in the wider area of interest of Respiratory Medicine.

With this short note, we would like to invite you to join the Pneumon family, both as committed authors and as readers, and we warmly welcome your submissions and look forward to your readership.

\section{CONFLICTS OF INTEREST}

The author has completed and submitted an ICMJE Form for Disclosure of Potential Conflicts of Interest. The author declares that he has no competing interests, financial or otherwise, related to the current work. The author declares grants, consulting fees and honoraria from AstraZeneca, Boehringer Ingelheim, Chiesi, ELPEN, GSK, Menarini, and Novartis, grants from Innovis and NuvoAir, consulting fees from CSL Behring and Sanofi Genzyme, and honoraria from Sanofi Genzyme and WebMD, all outside the submitted work. Furthermore, the author reports being member of the GOLD Assembly.

\section{FUNDING}

There was no source of funding for this research.

\section{ETHICAL APPROVAL AND INFORMED CONSENT}

Ethical approval and informed consent were not required for this study.

\section{DATA AVAILABILITY}

Data sharing is not applicable to this article as no new data were created.

\section{PROVENANCE AND PEER REVIEW}

Not commissioned; internally peer reviewed.

\section{REFERENCES}

1. Committee on Publication Ethics. Code of conduct and best practice guidelines for journal editors. COPE; 2011. Accessed September 29, 2021. https://publicationethics.org/files/ Code_of_conduct_for_journal_editors_Mar11.pdf

2. International Committee of Medical Journal Editors. Recommendations. ICMJE; 2017. Updated 2019.
Accessed September 29, 2021. http://www.icmje.org/ recommendations/ 